\title{
Citric Acid Production From Sugarcane Bagasse through Solid State Fermentation Method Using Aspergillus niger Mold and Optimization of Citric Acid Production by Taguchi Method
}

\author{
Masoud Yadegary ${ }^{1}$, Adel Hamidi ${ }^{2}$, Seyed Abolhasan Alavi ${ }^{3}$, Ebrahim Khodaverdi ${ }^{4}$, Hamid \\ Yahaghi ${ }^{5}$, Sara Sattari ${ }^{6}$, Ghasem Bagherpour ${ }^{7}$, Emad Yahaghi ${ }^{8,}$ \\ ${ }_{2}^{1}$ Department of Chemistry, Tehran Branch, Science and Research Islamic Azad University, Tehran, IR Iran \\ 2 Department of Microbiology, Razi Vaccine and Serum Research Institute, Arak, IR Iran \\ ${ }_{3}^{3}$ Department of Chemistry Engineering, Tehran Branch, Science and Research Islamic Azad University, Tehran, IR Iran \\ ${ }_{5}^{4}$ Young Researchers and Elite Club, Karaj Branch, Islamic Azad University, Karaj, IR Iran \\ 5 Department of Microbiology, Science and research Branch, Islamic Azad University, Damghan, IR Iran \\ 6 Department of Microbiology, Science and research Branch, Islamic Azad University, Tehran, IR Iran \\ ${ }^{7}$ Department of Biotechnology, Pasteur institute of Iran, Tehran, IR Iran \\ ${ }^{8}$ Chemical injuries research center, Baqiyatallah university of medical sciences, Tehran, Iran. \\ ${ }^{*}$ Corresponding author. Emad Yahaghi, Chemical injuries research center, Baqiyatallah university of medical sciences, Tehran, Iran. Tel/fax: +98-2177551919, E-mail: emadyahaghi10@ \\ yahoo.com
}

Received: August 7, 2012; Revised: December 18, 2012; Accepted: December 22, 2012

\begin{abstract}
Background: Citric acid is produced in insignificant quantities in Iran. Despite its great range of utilizations, and from another aspect, high level of production of sugarcane bagasse, the related problems arising from maintenance of this acid require thinking of a measure in the direction of its optimal usage and production.

Objectives: The objective of the present study is to obtain effectual variables in producing citric acid from sugarcane bagasse through Solid State Fermentation (SSF) method using Aspergillus niger mold and to optimize its mass production by employing Taguchi method. Materials and Methods: The effective parameters such as spore inoculation level, methanol percentage, solvent type, spore age, humidity percentage, initial $\mathrm{pH}$ of substrate, fermentation period and temperature, initial sugar percentage, autoclaving duration, nitrogen source and etc. were studied for producing citric acid from sugarcane bagasse with respect to Tagouchi method.

Results: By considering the findings obtained from the tests, the highest production rate of citric acid $\mathrm{g} / \mathrm{kg}$ out of untreated sugarcane bagasse is 75.45 based on the consumed sugar and a yield of $15.1 \mathrm{~g} / \mathrm{kg}$ of sugarcane was achieved per day. Application of sodium hydroxide and acid pretreated sugarcane bagasse increased the production of citric acid in such a fashion that the production rates were $97.81 \mathrm{~g} / \mathrm{kg}$ and $87.32 \mathrm{~g} / \mathrm{kg}$ of sugarcane bagasse, respectively, compared to sodium hydroxide and acid untreated sugarcane bagasse.

Conclusions: The obtained findings in the present study indicated that sugarcane bagasse is an ideal substrate in producing citric acid and the aforementioned process could be considered as a beneficial and cost-effective method in citric acid production.
\end{abstract}

Keywords: Citric Acid; Sugarcane; Bagasse; Aspergillus niger

\section{Background}

Biotechnology is the science of utilizing live creatures' vital forces for the purpose of yielding various products. One of these products to be mentioned is citric acid which exists naturally in plants and animals, and is produced by many molds, yeasts, and bacteria. For the first time in 1784, this acid was extracted from lemon juice in crystal form by Shiel, and Grimmoks. Another researcher by the name of Adams produced citric acid chemically in 1880. Also in 1917, citric acid production through fermentation got underway utilizing Aspergillus niger based on Curry's studies, and today this method is used for industrial production $(1,2)$.

In its industry, citric acid is one of the major fermented products which can be produced through three methods: floating culturing, superficial culturing, and solid state fermentation (SSF). The phrase "solid state" is used for an environment within which an organism freely grows on solid substances devoid of any liquid. Approximately one fifth of citric acid production in Japan is done by solid state culturing method (3-5).

Considering various applications of citric acid in different industries and the intense competition existing throughout the different regions of the world among producers of this product, many attempts have been made in order to diminish its production costs. Concerning this matter, numerous studies have been conducted with the intention of using food remnants to make citric acid. To exemplify some, remnants of apple, grapes, 
coffee, dates, corn cob, sugarcane molasses, wheat straw and moss may be mentioned.

Although the industrial production of citric acid approximately began during 1920 , it presently has a very low production level with respect to its abundant consumption in Iran and a great deal of the country's currency is annually allocated to its import. On the other hand, the high level of sugarcane bagasse production after the completion of Khuzestan province projects (three million tons per year) and the problems caused due to its storage require a comprehensive measurement in the direction of its optimized utilization and citric acid production (6-16).

Designing trials for a statistical method in assessing the effects of various parameters upon one variable is the answer. Fundamentally, designing trials from the common methods of data collection regarding the effects and answers is more effectual and unabridged. More especially, it has been proven that the preliminary method for surveying the effectiveness of a factor while the other factors are kept constant has less efficiency. In designing trials, different factors, which are envisaged to be more effective upon a process while considering the acceptable limits (levels) for them, are selected. In this event, any combination of the quantities of factors is regarded as a method. The objective of finding a specific composition of any given factor level is what brings about the most desirable effect on the process. Detecting the fact that what sorts of entering and exiting variables have constituted the process under scrutiny is essential. As usual, the objective is to improve an exiting variable commonly called the corresponding variable $(2,4,6)$.

Taguchi Method suggests 12 trials for examining $11 \mathrm{fac}-$ tors at two levels. By considering a total number of all possible combinations involving these 11 factors at two levels, 2048 trials $(211=2048)$ are necessary to include all possible situations (complete factorial). However, while using statistical methods from the total number of 2048 trials, Taguchi Method specifies and suggests a total of 12 trials which possess the 12 involving factors within much effectiveness.

\section{Objectives}

Regarding the cost and considering the level of production in sugar plants, especially in Khuzestan region, sugarcane bagasse is an extremely suitable substrate for citric acid production. One of the advantages of SSF compared to supernatant fermentation is reductions in industrial sewage, production cost, and volume of wastes. The objective of the present study is to obtain effectual variables in producing citric acid from sugarcane bagasse by SSF method using A. niger and to optimize its mass production.

\section{Materials and Methods}

\subsection{Microorganism}

The microorganism under investigation was A. niger PTCC 5010 (ATCC 9142) which was obtained from the Department of Scientific and Industrial Research of Iran. The microorganism was grown on specific Potato Dextrose Agar (PDA, Merck Company, USA) culture media, slants, and it was incubated at $30^{\circ} \mathrm{C}$ for five days. The cultures were later refrigerated at $4^{\circ} \mathrm{C}$. In order to prevent inactivity and possible contamination of the inoculums, new subcultures were prepared every month. For the purpose of preparing spore suspension, sterile distilled water was added to the 4-day old or 6 day-old cultures. After separating spores by immersing them in sterile distilled water, spore count was performed by microscope using Neubauer slide method and the desired densities were obtained.

\subsection{Substrate}

The sugarcane bagasse used in this study was obtained from Haft-Tapeh sugar plant in Khuzestan province and it was stored at room temperature. The grain size was considered to be between 1 to $1.6 \mathrm{~mL}$. Appropriately puncturing the medium lids facilitated and optimized oxygen penetration, as well proper ventilation of the heat produced during fermentation process (17). With the reduction of the grains' size, their interspaces dwindled and their tendency for compaction increased. As a result, a decrease occurred in the transport of oxygen mass. On the other hand, with the enlargement of the grains, the chance for the microorganisms to access bagasse grains was reduced. Therefore, by considering the produced research findings, the sugarcane bagasse was grinded.

\subsection{Fermentation Process}

From the completely dried substrate, $4 \mathrm{~g}$ were emptied into a $250 \mathrm{~mL}$ Erlenmeyer flasks and after setting their $\mathrm{pH}$ on 4 or 5.5 , moisture on $65 \%$ or $75 \%$, initial sugar on $14 \%$ or $18 \%(\mathrm{v} / \mathrm{v})$, urea source on $2 \%$ or $4 \%$, and methanol on $3 \%$ or $4 \%(\mathrm{v} / \mathrm{v})$, they were sterilized in an autoclave at $121^{\circ} \mathrm{C}$ for 20 or 90 minutes. (In order to sterilize urea, a filter with pores of $2 \mu \mathrm{m}$ in diameter was used instead of autoclaving. After the Erlenmeyer flasks cooled, the filtered solution was added to them, in order to avoid urea degradation. In the present study, autoclave was used to implement steam parameter on bagasse substrate so that both processes of steaming and sterilizing could be performed simultaneously. Therefore, periods of 20 to 90 minutes are for autoclaving the raw materials instead of 15 minutes for implementing steaming parameter). After drying in sterile conditions, a spore suspension with the counts of $1 \times 10^{5}$ or $1 \times 10^{7}$ (spore $/ \mathrm{mL}$ ) was inoculated into each flask. The inoculated flasks were incubated at temperatures between $25^{\circ} \mathrm{C}$ and $30^{\circ} \mathrm{C}$ for 4 to 5 days.

\subsection{Leaching}


Extraction of the produced citric acid from the solid state fermented mediums was performed by adding sterile distilled water at two stages or by single-stage addition of sterile distilled water and single stage-addition of acetone with volumes of $150 \mathrm{~mL}$ per each medium, and thoroughly mixing for 30 minutes. The liquid-solid phase separation process was then continued with the aid of filtering and centrifuging. After this stage, the levels of the yielded citric acid and the remaining sugar existing in the liquid phase were measured.

\subsection{Determining Methods}

$\mathrm{pH}$ determination was conducted by a pH-meter, using $10 \%$ aqueous solution. The initial and remaining sugar levels were measured by dinitrosalicylic acid (DNS) method while the level of citric acid was measured using acetic anhydride pyridine method $(18,19)$.

\subsection{Taguchi Design Method}

The very first step in this method is to recognize those variables which significantly influence the production of citric acid with $A$. niger mold. For the purpose of intensifying the growth of $A$. niger mold and increasing its subsequent citric acid production, effective factors and their related levels were selected based on previous studies. The assessed factors include the medium conditions and the environmental factors which are displayed in the following tables. These tables demonstrate Taguchi design for conducting 12 trials along with 11 variables at two levels. Number one is indicative of the low level and number two is indicative of the high level of each variable (Tables 1 and 2).

Table 1. Utilized Parameters and Their Levels in Implementing Taguchi Method for the Production of Citric Acid Using Bagasse Substrate in Solid State Fermentation

\begin{tabular}{|c|c|c|c|c|}
\hline Level 2 & Level 1 & Limit & Processing Parameter & Symbol of Parameter \\
\hline $10^{7}$ & $10^{5}$ & $10^{5}-10^{7}$ (spore $\left./ \mathrm{mL}\right)$ & inoculation level & A \\
\hline $4 \%$ & $3 \%$ & $3 \%-4 \%$ & methanol percentage & B \\
\hline Acetone solution & water & acetone-water solvent & solvent type & $\mathrm{C}$ \\
\hline $6 \mathrm{~d}$ & $4 \mathrm{~d}$ & $4-6 d$ & spore age & $\mathrm{D}$ \\
\hline $75 \%$ & $65 \%$ & $65 \%-75 \%$ & moisture percentage & $\mathrm{E}$ \\
\hline 5.5 & 4 & $4-5.5$ & initial pH & $\mathrm{F}$ \\
\hline $5 \mathrm{~d}$ & $4 \mathrm{~d}$ & $4-5 d$ & fermentation period & G \\
\hline $30^{\circ} \mathrm{C}$ & $25^{\circ} \mathrm{C}$ & $25^{\circ} \mathrm{C}-30^{\circ} \mathrm{C}$ & fermentation temperature & $\mathrm{H}$ \\
\hline $18 \%$ & $14 \%$ & $14 \%-18 \%$ & initial sugar & I \\
\hline $4 \%$ & $2 \%$ & $2 \%-4 \%$ & nitrogen source & $\mathrm{J}$ \\
\hline $90 \mathrm{~min}$ & $20 \mathrm{~min}$ & 20 to $90 \mathrm{~min}$ & steam implementation period & $\mathrm{K}$ \\
\hline
\end{tabular}

Table 2. Optimized Quantities and Parameters Which Were Predicted by Taguchi for Higher Citric Acid Production Quantities Using Sugarcane Bagasse Substrate

\begin{tabular}{llll}
\hline $\begin{array}{l}\text { Optimized Quantity, Pre- } \\
\text { treated With Acid }\end{array}$ & $\begin{array}{l}\text { Optimized Quantity, Pre- } \\
\text { treated With Alkaline }\end{array}$ & $\begin{array}{l}\text { Optimized Quantity, un- } \\
\text { Pretreated }\end{array}$ & Trial \\
\hline $\mathbf{1 0}^{5}, \mathbf{c f u} / \mathbf{m L}$ & $10^{5}, \mathrm{cfu} / \mathrm{mL}$ & $10^{5}, \mathrm{cfu} / \mathrm{mL}$ & Inoculation, $\%$ \\
\hline $\mathbf{4} \%$ & $4 \%$ & $4 \%$ & Methanol, $\%$ \\
\hline $\mathbf{5 0} \%$ acetone solution & $50 \%$ acetone solution & $50 \%$ acetone solution & Solvent type \\
\hline $\mathbf{6 ~ d}$ & $6 \mathrm{~d}$ & $6 \mathrm{~d}$ & Spore age \\
\hline $\mathbf{6 5} \%$ & $65 \%$ & $75 \%$ & Moisture, $\%$ \\
\hline $\mathbf{4}$ & 5.5 & 5.5 & Initial pH \\
\hline $\mathbf{4 d}$ & $5 \mathrm{~d}$ & $5 \mathrm{~d}$ & Fermentation period \\
\hline $\mathbf{2 5} \mathbf{C}^{\circ} \mathbf{C}$ & $30^{\circ} \mathrm{C}$ & $30^{\circ} \mathrm{C}$ & Fermentation temperature \\
\hline $\mathbf{1 8} \%$ & $18 \%$ & $14 \%$ & Initial sugar, $\%$ \\
\hline $\mathbf{9 0} \mathbf{~ m i n}$ & $20 \mathrm{~min}$ & $20 \mathrm{~min}$ & Steam implementation period \\
\hline- & - & $4 \%$ & Nitrogen source percentage \\
\hline $\mathbf{1 N}$ & - & - & Acid normality \\
\hline- & $1 \mathrm{M}$ & - & Alkaline molarity \\
\hline
\end{tabular}




\section{Results}

\subsection{Methanol Effect}

The findings exhibit that the high level of methanol ( $4 \%$ $\mathrm{v} / \mathrm{v}$ ) yields the maximum amount.

\subsection{Initial Moisture Effect}

With respect to the obtained findings, it is specified that the highest yields arise from the untreated bagasse at 65\% moisture, while for sodium hydroxide and acid pretreated bagasse at 75\% moisture, respectively.

\subsection{Fermentation Temperature and Time Effect}

The optimum fermentation temperature for citric acid production in this study was determined to be $30^{\circ} \mathrm{C}$ for both untreated and sodium hydroxide pretreated bagasse, whereas $25^{\circ} \mathrm{C}$ is optimum for acid treated bagasse. The fermentation time for five days was also considered for both untreated bagasse and sodium hydroxide pretreated bagasse, while it was five days for acid pretreated bagasse.

\subsection{The Effect of Spore Age and the Level of Inoculation}

For the purpose of high yields of citric acid from sugarcane bagasse, $A$. niger was grown on PDA slant media for a period of 6 days. A quantity of $10^{5}$ (Spore/mL) from the organism was inoculated on the media.

\subsection{Sugar Concentration Effect}

According to the obtained findings, the suitable initial sugar concentration for the highest citric acid yields is $18 \%(\mathrm{v} / \mathrm{v})$.

\subsection{The Effect of Acetone Utilization on Leaching Process}

The present study revealed that in comparison to water, acetone has a greater influence in the extraction process.

\subsection{The Effect of Adding a Nitrogen Source}

Studies have shown that the highest yields of citric acid production from sugarcane bagasse are obtained through the addition of urea up to $4 \%(\mathrm{v} / \mathrm{v})$ as a nitrogen source.

\subsection{The Effect of Steam Application Time}

The findings from the present study exhibited that a period of 20 minutes was the steam application time for untreated bagasse and sodium hydroxide pretreated bagasse. A period of 90 minutes was the steam application time for acid pretreated bagasse which yielded the high- est quantity of citric acid.

\section{Discussion}

In the present study, citric acid production from sugarcane bagasse with $A$. niger mold was studied through SFF method. Using methanol with the intention of augmenting the production of citric acid was first implemented by Moyer in 1953. Methanol intensifies the outbound permeability of the cellular walls for secretion of citric acid. The methanol's effect in producing citric acid depends on osmotic pressure. From another aspect, methanol operates as a source of carbon $(17,19,20)$.

One of the important and effective factors in SSF is the initial moisture of the substrate. The osmotic pressure of a substrate is determined by the substrate's nature, its biological needs, and the final product. Excessive rise of moisture level causes reduction in grains' interspaces and failure in transport of air mass. In contrast, excessive drop of moisture level causes a decrease in transport of air mass and thus causing a reduction in the production yields $(6,21-23)$.

Citric acid production has a maximum point with respect to temperature and time. Crossing beyond this maximum point, the growth and intensive sporolation of the microorganism cause a halt in the overall growth, and consequently the production of citric acid decreases. At the time of fermentation, it is not a simple task to suggest a particular model for growing the microorganism on a solid state because such growth is more similar to the one in the natural environment and the quantities of the ideal nutrients available in the substrate are not sufficient $(24,25)$.

Fernandez and his colleagues suggested that the highest level of citric acid is produced when the age of spores is less than seven days, because older spores tend to consume the initially produced acid before the fermentation process is completed (25). The increase in the number of inoculated spores primarily increases the level of acid production, however, in the long run this increase tends to force the process toward cellular crowding and to favor the consumption of sugar for biomass reproduction, thus resulting in a reduction in production of citric acid. The excessive reduction in the level of inoculation also causes prolongation in the adaptation phase, therefore decreasing an ideal outcome $(24,26)$.

The effective sugar concentration for industrial fermentation must be $\% 14$ to $22 \%$ in SSF method. Since the dissolved sugar concentration in the sugarcane bagasse being utilized was at $2 \%$ to $3 \%$ and it was lower than the required limit, sugarcane molasses was used to increase the initial sugar concentration in the substrate (27). Leaching of citric acid with acetone led to an increase in the extraction percentage with respect to water and considering the low boiling point of this solvent $\left(56.2^{\circ} \mathrm{C}\right)$, its recovery and reutilization are conceivable (28). 
When A. niger is added to a medium which is either low in or free of nitrogen, it produces as much oxalic acid as citric acid. However, an increase in nitrogen source produces opposite results and it causes an increase in microorganism's growth and a decrease in citric acid production (24). Subjecting the substrate to steaming could function as a physical pretreatment. For this reason, steaming becomes the cause in increasing citric acid production. Pretreatment with steam causes breakage of hemicellulos and pectinaceous acetyl and formil groups bonds, depolymerization of lignin, and increase in both the cellular wall permeability and the water storage capacity for bagasse substrate (29).

By noting the findings which were achieved, this fact was established that through implementation of a pretreatment process on sugarcane bagasse, the level of acid citric production dramatically increases. Among the pretreatments implemented on sugarcane bagasse, pretreatment with sodium hydroxide produced the best result in such manner that citric acid production increased from $75.45 \mathrm{~g} / \mathrm{kg}$ to $97.81 \mathrm{~g} / \mathrm{kg}$ while the output for production with pretreatment with sodium hydroxide was reported at $98.2 \%$. But, on the other hand, the production output in pre-treating with acid, amounting to $21.8 \mathrm{~g} / \mathrm{kg}$ of substrate per each day, was higher than other testing conditions. Optimization of the environmental conditions plays a significant role in the production process of citric acid; increasing production output drastically (Table 3 ).

Table 3. Confirmation of Predicted Results by Designing Optimized Taguchi Method for Higher Citric Acid Quantities Production Using Sugarcane Bagasse Substrate

\begin{tabular}{llll}
\hline Pretreated Bagasse & Bagasse Pretreated with Acid & $\begin{array}{l}\text { Bagasse Pretreated With } \\
\text { Alkaline }\end{array}$ & Trial \\
\hline $\mathbf{1 4} \%$ & $18 \%$ & $18 \%$ & \% of initial sugar \\
$\mathbf{0 . 2 8 3}$ & 0.47 & 0.486 & sugar absorption \\
$\mathbf{5 . 7 8} \%$ & $7.64 \%$ & $7.8 \%$ & \% of remnant sugar \\
$\mathbf{0 . 1 8 9}$ & 0.215 & 0.238 & acid absorption \\
$\mathbf{1}$ & 1.16 & 1.3 & acid yield, $\mathrm{g} / \mathrm{L}$ \\
$\mathbf{7 5 . 4 5}$ & 87.32 & 97.81 & acid yield, $\mathrm{g} / \mathrm{kg}$ \\
$\mathbf{1 . 0 7}$ & 1.35 & 1.33 & sugar consumption, $\mathrm{g} / \mathrm{L}$ \\
$\mathbf{9 4}$ & 86.3 & 98.2 & efficiency \\
$\mathbf{1 5 . 1}$ & 21.8 & 19.6 & outcome, $\mathrm{g} / \mathrm{kg} / \mathrm{d}$ \\
\hline
\end{tabular}

By assessing the obtained findings and considering the fact that for citric acid production, sugarcane bagasse is an appropriate substrate from the cost point of view, it is highly possible to consider this process as a beneficial and cost-effective method. Additionally, after leaching and extracting citric acid from fermented cultures, and destroying microorganisms, remnant materials could be used as animal food because SSF decreases the concentration of anti-nutritional factors in such materials.

\section{Acknowledgements}

We thank all the personnel who helped us accomplish this project.

\section{Authors' Contribution}

Masoud Yadegary: first author; Adel Hamidi and seyed Abolhasan Alavi: data collection; Ebrahim Khodaverdi and Hamid Yahaghi: data analysis; Sara Sattari: data analysis; Emad Yahaghi: corresponding author; Ghasem Bagherpour: data collection.

\section{Financial Disclosure}

All required materials have been received from Razi In- stitute.

\section{Funding/Support}

All of the authors supported this study.

\section{References}

1. Angumeenal AR, Venkappayya D. An overview of citric acid production. Food Sci Technol. 2013;50(2):367-370.

2. Singh Dhillon G, Kaur Brar S, Verma M, Tyagi RD. Recent Advances in Citric Acid Bio-production and Recovery. Food Bioprocess Technol.2010;4(4):505-529.

3. Khosravi-Darani K, Zoghi A. Comparison of pretreatment strategies of sugarcane baggase: experimental design for citric acid production. Bioresour Technol.2008;99(15):6986-93.

4. Hattori T, Kino K, Kirimura K. Regulation of alternative oxidase at the transcription stage in Aspergillus niger under the conditions of citric acid production. Curr Microbiol. 2009;58(4):321-5.

5. Hang YD, Woodams EE. Solid state fermentation of apple pomace for citric acid production. Mircen J Appl Microbiol Biotechnol. 1986;2(2):283-287.

6. Barrington S, Kim JW. Response surface optimization of medium components for citric acid production by Aspergillus niger NRRL 567 grown in peat moss. Bioresour Technol. 2008;99(2):368-77.

7. Acourene $S$, Ammouche A. Optimization of ethanol, citric acid, and alpha-amylase production from date wastes by strains of Saccharomyces cerevisiae, Aspergillus niger, and Candida guilliermondii.J Ind Microbiol Biotechnol. 2012;39(5):759-66.

8. Ramesh T, Kalaiselvam M. An Experimental Study on Citric Acid Production by Aspergillus niger Using Gelidiella acerosa as a 
Substrate. Indian J Microbiol. 2011;51(3):289-93.

9. Rywinska A, Musial I, Rymowicz W, Zarowska B, Boruczkowski T Effect of agitation and aeration on the citric acid production by Yarrowia lipolytica grown on glycerol. Prep Biochem Biotechnol. 2012;42(3):279-91.

10. Rymowicz W, Fatykhova AR, Kamzolova SV, Rywinska A, Morgunov IG. Citric acid production from glycerol-containing waste of biodiesel industry by Yarrowia lipolytica in batch, repeated batch, and cell recycle regimes. Appl Microbiol Biotechnol. 2010;87(3):971-9.

11. Vyas P, Gulati A. Organic acid production in vitro and plant growth promotion in maize under controlled environment by phosphate-solubilizing fluorescent Pseudomonas. BMC Microbiol. 2009;9:174.

12. Kim JW, Barrington S, Sheppard J, Lee B. Nutrient optimization for the production of citric acid by Aspergillus niger NRRL 567 grown on peat moss enriched with glucose. Process Biochem. 2006;41(6):1253-1260.

13. Vahab Zade F, Amiri S. Citric acid production from chemistry treatmented sugarcane molasses by fixed cells of Aspergillus niger. Amirkabir. 2009;12(46):163-167.

14. Zoghi A, Khosravi Darani K, Alavi SA, Fatemi SSA. Citric acid production from wheat straw by Aspergillus niger mold. Microbiol Sci. 2008;18(2):32-41.

15. Hosseini M, Rezazad Bari M, Alizadeh Khaledabad M. Evaluation of Citric Acid Production from Apple Pomace Using Surface Culture Method. Food Sci Technol. 2009;19(1):35-42.

16. Rashedi H, Mazaheri Asadi M. Optimization Citric acid production from date wastes using liquid state method. Danesh Microbiol. 2009;1(1):1-10.

17. Anastassiadis S, Morgunov IG, Kamzolova SV, Finogenova TV. Citric acid production patent review. Recent Pat Biotechnol. 2008;2(2):107-23.

18. Papanikolaou S, Fakas S, Fick M, Chevalot I, Galiotou-Panayotou $\mathrm{M}$, Komaitis M, et al. Biotechnological valorisation of raw glycerol discharged after bio-diesel (fatty acid methyl esters) manu- facturing process: Production of 1,3-propanediol, citric acid and single cell oil. Biomass Bioenergy. 2008;32(1):60-71.

19. Imandi SB, Bandaru VV, Somalanka SR, Bandaru SR, Garapati HR Application of statistical experimental designs for the optimization of medium constituents for the production of citric acid from pineapple waste. Bioresour Technol. 2008;99(10):4445-50.

20. Papanikolaou S, Galiotou-Panayotou M, Fakas S, Komaitis M, Aggelis G. Citric acid production by Yarrowia lipolytica cultivated on olive-mill wastewater-based media. Bioresour Technol. 2008;99(7):2419-28.

21. Dhillon GS, Brar SK, Verma M, Tyagi RD. Apple pomace ultrafiltration sludge - A novel substrate for fungal bioproduction of citric acid: Optimisation studies. Food Chem. 2011;128(4):864-871.

22. Hanson JR. The chemistry offungal.London: Royal Society of Chemistry; 2008.

23. Karthikeyan A, Sivakumar N. Citric acid production by Koji fermentation using banana peel as a novel substrate. Bioresour Technol. 2010;101(14):5552-6.

24. Alam MZ, Bari MN, Muyibi SA, Jamal P, Abdullah Al M. Development of Culture Inoculum for Scale-Up Production of Citric Acid from Oil Palm Empty Fruit Bunches by Aspergillus niger. Procedia Environ Sci. 2011;8:396-402.

25. Kirimura K, Honda Y, Hattori T. Citric Acid. Comp Biotechnol. 2011;3:135-142.

26. Dhillon GS, Brar SK, Kaur S, Verma M. Bioproduction and extraction optimization of citric acid from Aspergillus niger by rotating drum type solid-state bioreactor. Ind Crops Prod. 2013;41:7884.

27. Rohr M, Kubicek CP, Kominek J. Citric acid in Biotechnology. Microb prod. 2008;24:420-454.

28. Dhillon GS, Brar SK, Verma M, Tyagi RD. Utilization of different agro-industrial wastes for sustainable bioproduction of citric acid by Aspergillus niger. Biochem Eng J. 2011;54(2):83-92.

29. Liu JX, Orskov ER. Cellulase treatment of untreated and steam pre-treated rice straw-effect on in vitro fermentation characteristics. Animal Feed Sci Technol. 2000;88(3):189-200. 